Int. J. Electrochem. Sci., 14 (2019) 7973 - 7982

\title{
Generalized Peukert's Equation for Nickel-Cadmium Batteries at High Discharge Currents
}

\author{
Nataliya N. Yazvinskaya, Nikolay E. Galushkin*, Dmitriy N. Galushkin, Andrey V. Alepko \\ Don State Technical University, Laboratory of electrochemical and hydrogen energy, 147 Shevchenko \\ Street, Town of Shakhty, Rostov Region, Russia, 346500. \\ *E-mail: galushkinne@mail.ru
}

doi: $10.20964 / 2019.08 .50$

Received: 3 April 2019 / Accepted: 21 May 2019 / Published: 30 June 2019

In this paper both experimentally and theoretically, the dependence was analyzed of released capacity of nickel-cadmium batteries at diverse discharge currents. It was shown that the classical Peukert's equation is inapplicable at both small and high discharge currents. Meanwhile, the well-known generalized Peukert's equation $C=C_{m} /\left(1+(i / i 0)^{\mathrm{n}}\right)$ corresponds well to the experimental data at small and medium discharge currents. However at high discharge currents, the capacity released by nickelcadmium batteries is diminished much faster than this generalized Peukert's equation predicts. By experiments and theoretically, it was proved that the reason of the sharper descent of the batteries' released capacity at high discharge currents is the voltage loss escalation on battery internal resistance at a growth of discharge current. There was proposed the equation $C=C_{m} /\left(1+i^{\mathrm{n}} /\left(i 0^{\mathrm{n}}(1-i / i 1)\right)\right)$ taking into account this effect; and this one corresponds well to the experimental data at any discharge currents.

Keywords: Peukert's equation, modeling, battery, nickel-cadmium, discharge current

\section{FULL TEXT}

(C) 2019 The Authors. Published by ESG (www.electrochemsci.org). This article is an open access article distributed under the terms and conditions of the Creative Commons Attribution license (http://creativecommons.org/licenses/by/4.0/). 